\title{
Flutter Characteristic Study of Composite Sandwich Panel with Functionally Graded Foam Core
}

\author{
Peng Jin ${ }^{1}$ and Xiaoping Zhong ${ }^{2}$ \\ ${ }^{1}$ School of Civil Engineering and Architecture, Xian University of Technology, Xian 710048, China \\ ${ }^{2}$ School of Aeronautics, Northwestern Polytechnical University, Xian 710072, China \\ Correspondence should be addressed to Xiaoping Zhong; zxp_proteus@nwpu.edu.cn
}

Received 3 May 2016; Accepted 10 October 2016

Academic Editor: Hikmat Asadov

Copyright (c) 2016 P. Jin and X. Zhong. This is an open access article distributed under the Creative Commons Attribution License, which permits unrestricted use, distribution, and reproduction in any medium, provided the original work is properly cited.

\begin{abstract}
This paper attempts to investigate the flutter characteristic of sandwich panel composed of laminated facesheets and a functionally graded foam core. The macroscopic properties of the foam core change continuously along this direction parallel to the facesheet lamina. The model used in the study is a simple sandwich panel-wing clamped at the root, with three simple types of grading strategies for FGM core: (1) linear grading strategy in the chord-wise direction, (2) linear grading strategy in the span-wise direction, and (3) bilinear grading of properties of foam core across the panel. The results show that use of FGM core has the potential to increase the flutter speed of the sandwich panel. Finally, a minimum weight design of composite sandwich panel with lamination parameters of facesheet and density distribution of foam core as design variables is conducted using particle swarm optimization (PSO).
\end{abstract}

\section{Introduction}

Aeroelastic phenomena are the result of the mutual interaction of elastic and aerodynamic forces, the occurrence of which during the flight can be destructive and lead to the loss of the aircraft [1]. The stiffness and mass distribution of the wing structure both have effects on the aeroelastic properties. Functionally graded materials have continuously varying properties by spatially varying the distribution of two (or more) materials. FGMs enable changes in structural stiffness and mass distribution without necessarily requiring a geometric change in the structural geometry, so FGM can be a novel aeroelastic tailoring concept [2]. The idea of using functionally graded materials for aeroelastic tailoring is not totally new. For high-speed aircraft, many researchers [3-6] have studied on the thermal flutter analysis of functionally graded materials (FGMs) plates with mechanical properties varying through the thickness. This is because the distribution of temperature is important in affecting the thermal flutter behavior, so FGMs have been shown in these papers to improve the aerothermoelastic panel flutter boundaries [2]. For low-speed structures, Kuo [7] investigated the flutter analysis of composite plates with variable fiber spacing.
Librescu and Maalawi [8] researched the torsional divergence stability of a cantilevered wing using material fiber volume fraction grading of composite materials to optimize the material distribution. Dunning et al. [2] studied the efficiency of FGM for the aeroelastic tailoring of a metallic cantilever plate-like wing using both material grading and geometric grading and concluded that an FGM can be used to improve the performance of a plate-like wing compared with a uniform material design. Dunning et al. fill a gap in the literature pertaining to FGM-based aeroelastic tailoring by considering a metallic wing in low-speed (subsonic) conditions.

Based on author's previous research [9], this paper considers the low-speed flutter behavior of a clamped plate-wing, whose structure is composed of laminated facesheets and a functionally graded foam core. The present study aims to consider the flutter characteristic of sandwich panel with the macroscopic properties of the foam core changing continuously along this direction parallel to the facesheet lamina. The model used in the study is a simple sandwich panel clamped at the root, with three simple types of grading strategies for FGM core according to [2]: (1) linear grading strategy in the chord-wise direction, (2) linear grading strategy in the 
TABLE 1: Material property of T300/QY891.

\begin{tabular}{lccccc}
\hline$E_{11}(\mathrm{GPa})$ & $E_{22}(\mathrm{GPa})$ & $\mu_{12}$ & $G_{12}(\mathrm{GPa})$ & $\rho_{\text {face }}\left(\mathrm{kg} / \mathrm{m}^{3}\right)$ & $t_{\text {ply }}(\mathrm{mm})$ \\
\hline 127.56 & 13.03 & 0.3 & 6.41 & 1577.76 & 0.125 \\
\hline
\end{tabular}

span-wise direction, and (3) bilinear grading of properties of foam core across the panel. For a typical sandwich panel with a thick core $\left(t_{\text {face }} / t_{\text {core }} \ll 1\right)$, the bending and transverse shear stiffness of the facesheet itself can be neglected. In the present study, composite sandwich stiffness matrix is calculated using lamination parameters of composite facesheets for a thick sandwich panel, and the flutter speed of composite sandwich panel is studied using lamination parameters, with influence of foam density distribution and shear modulus distribution on flutter speed considered.

\section{Equivalent Stiffness Matrix of Sandwich}

In a cantilevered composite sandwich panel $(1.2 \mathrm{~m} \times 0.4 \mathrm{~m})$ with one end fixed, thicknesses of facesheet and foam core are $0.0005 \mathrm{~m}$ and $0.01 \mathrm{~m}$. The material properties of T300/QY8911 used for composite facesheet are listed in Table 1. Poisson's ratio of isotropic material property of foam core is $v_{\text {core }}=$ 0.25 .

The sandwich stiffness matrices can be written in terms of the facesheet and core stiffness as follows [10]:

$$
\begin{aligned}
& A_{\text {Sandwich }}=2 A_{\text {Face }}, \\
& D_{\text {sandwich }}=2 A_{\text {Face }}\left(\frac{t_{\text {core }}+t_{\text {face }}}{2}\right)^{2}, \\
& G_{\text {Sandwich }}=G_{\text {core }} .
\end{aligned}
$$

For composite facesheet, the membrane stiffness matrix can be expressed in terms of lamination parameters and material stiffness invariants:

$$
\begin{aligned}
A_{\text {Face }} & =\left[\begin{array}{l}
A_{11} \\
A_{22} \\
A_{12} \\
A_{66} \\
A_{16} \\
A_{26}
\end{array}\right]=t_{\text {face }}\left[\begin{array}{c}
A_{11}^{*} \\
A_{22}^{*} \\
A_{12}^{*} \\
A_{66}^{*} \\
A_{16}^{*} \\
A_{26}^{*}
\end{array}\right] \\
& =t_{\text {face }}\left[\begin{array}{ccc}
U_{1} & V_{1} & V_{2} \\
U_{1} & -V_{1} & V_{2} \\
U_{4} & 0 & -V_{2} \\
U_{5} & 0 & -V_{2} \\
0 & \frac{V_{3}}{2} & V_{4} \\
& \frac{V_{3}}{2} & V_{4}
\end{array}\right]\left[\begin{array}{c}
1 \\
U_{2} \\
U_{3}
\end{array}\right] .
\end{aligned}
$$

The material stiffness invariants are calculated as follows:

$$
\left\{\begin{array}{l}
U_{1} \\
U_{2} \\
U_{3} \\
U_{4} \\
U_{5}
\end{array}\right\}=\frac{1}{8}\left[\begin{array}{cccc}
3 & 2 & 3 & 4 \\
4 & 0 & -4 & 0 \\
1 & -2 & 1 & -4 \\
1 & 6 & 1 & -4 \\
1 & -2 & 1 & 4
\end{array}\right]\left\{\begin{array}{l}
Q_{11} \\
Q_{12} \\
Q_{22} \\
Q_{66}
\end{array}\right\},
$$

where $Q_{11}=E_{11} /\left(1-v_{12} v_{21}\right), Q_{22}=E_{22} /\left(1-v_{12} v_{21}\right), Q_{21}=$ $Q_{12}, Q_{66}=G_{12}$, and $v_{21}=v_{12}\left(E_{22} / E_{11}\right)$.

The membrane lamination parameters are given by the following integrals:

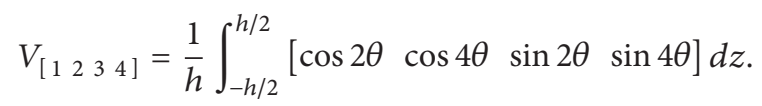

The lamination parameters cannot be chosen arbitrarily. For a laminate of $0,90,45$, and -45 degree fiber angles, $V_{4}=0$. Considering the dependency, the feasible domain for the inplane lamination parameters is known to be defined by [11]

$$
\begin{aligned}
& 2\left|V_{1}\right|-V_{2}-1 \leq 0, \\
& 2\left|V_{3}\right|+V_{2}-1 \leq 0
\end{aligned}
$$

\section{Gradient Material Properties of Foam Core}

For the density gradient foam material, to calculate Young's modulus of the closed-cell foam material, Xiao et al. [12] gave a modified equation based on the Gibson equation [13]:

$$
E_{f_{c}}=\left[\left(1-\frac{\rho_{f_{c}}}{\rho_{s}}\right)^{2}\left(\frac{\rho_{f_{c}}}{\rho_{s}}\right)^{2}+\left(\frac{\rho_{f_{c}}}{\rho_{s}}\right)^{2}\right] E_{s},
$$

where $E_{f_{c}}$ and $\rho_{f c}$ are the Young's modulus and mass density of closed-cell foam, respectively; $E_{s}$ and $\rho_{s}$ are the Young's modulus and mass density of the solid material of the cell wall, respectively. The material properties of the solid material are assumed: $E_{s}=100 \mathrm{MPa}$ and $\rho_{\mathrm{s}}=80 \mathrm{~kg} / \mathrm{m}^{3}$.

The flutter speed is always affected by the span-wise bending stiffness and chord-wise torsional stiffness for a wing panel. In order to research the flutter speed with grading bending and torsional stiffness, three types of grading strategies [2] are adopted to consider the grading transverse shear of foam core for composite sandwich flutter characteristics.

Grading Strategy 1 (GS1, shown as Figure 2(a)). Density grading in the chord-wise direction is as follows:

$$
\rho_{f_{c}}=\rho_{l}-\frac{x\left(\rho_{l}-\rho_{t}\right)}{b}
$$

where $\rho_{l}$ and $\rho_{t}$ are the mass densities of closed-cell foam of the leading edge and trailing edge, respectively; $b$ denotes the width of the panel.

Grading Strategy 2 (GS2, shown as Figure 2(b)). Density grading in the span-wise direction is as follows:

$$
\rho_{f c}=\rho_{r}-\frac{y\left(\rho_{r}-\rho_{t}\right)}{a},
$$


where $\rho_{r}$ and $\rho_{t}$ are the mass densities of closed-cell foam of the root edge and tip edge, respectively; $a$ denotes the length of the panel.

Grading Strategy 3 (GS3, shown as Figure 2(c)). Density diagonal grading across the $x y$ plane is as follows:

$$
\rho_{f c}=\frac{b-x}{b}\left(\frac{a-y}{a} \rho_{u}+\frac{y}{a} \rho_{l}\right)+\frac{x}{b}\left(\frac{a-y}{a} \rho_{l}+\frac{y}{a} \rho_{u}\right),
$$

where $\rho_{u}$ and $\rho_{l}$ are the mass densities of closed-cell foam of upper and lower bounds, respectively.

Submitting for $\rho_{f c}$ into (6), Young's modulus of DG closed-cell foam is obtained.

\section{Flutter Speed of Composite Sandwich Panel}

4.1. Aeroelastic Solution Methodology. PK-method method is adopted for flutter speed calculation [14]. The principal advantage of the PK-method is that it produces results directly for given values of velocity

$$
\begin{gathered}
{\left[M_{h h} p^{2}+\left(B_{h h}-\frac{1}{4} \frac{\rho c V Q_{h h}^{I}}{k}\right) p\right.} \\
\left.+\left(k_{h h}-\frac{1}{2} \rho V^{2} Q_{h h}^{R}\right)\right]\left\{u_{h}\right\}=0,
\end{gathered}
$$

where $M_{h h}, k_{h h}$, and $B_{h h}$ denote modal mass matrix, modal stiffness matrix, and modal damping matrix, respectively. $p$, $\rho, c$, and $V$ denote the eigenvalue, density, reference chord length, and velocity. $Q_{h h}^{R}$ and $Q_{h h}^{I}$ are modal aerodynamic force matrix and modal aerodynamic damping matrix, which are both functions of Mach number (Ma) and reduced frequency $(k)$. The divergence speed $V_{D}$ can be evaluated when $k$ tends to zero.

4.2. Flutter Speed Contours for Various Laminate Configurations. Keeping the total mass of the foam core constant and varying the densities of $\rho_{\text {core }}^{\min }$ and $\rho_{\text {core }}^{\max }$, the influence of the density gradient changes of the foam cores on the flutter speed is investigated. To describe the changing range of the mass density, the gradient factor (GF) is defined as the difference between $\rho_{\text {core }}^{\min }$ and $\rho_{\text {core }}^{\max }$ in Table 2 .

\subsubsection{Flutter Velocity Contour for Orthotropic Panel with} Gradient Foam. Orthotropic sandwich panel $\left(V_{3}=0\right.$ for facesheets) is investigated firstly, shown in Figure 3. The bending-torsional flutter of the orthotropic panel is due to coupling between the second bending mode and the first torsional mode, with the second mode as the critical vibration mode. The histories of the damping and frequency of the first four mode for the quasi-isotropic panel $\left(V_{1}=V_{2}=V_{3}=0\right)$ are illustrated in Figure 4. The critical flutter mode is the second mode.

Figure 5 gives the flutter velocity contours with various gradient change for orthotropic sandwich panel. For the three types of grading strategies, it is concluded that the flutter speed of the sandwich panel increases when the gradient
TABLE 2: Gradient factor.

\begin{tabular}{lcccc}
\hline Gradient factor (GF) & 0 & 1 & 2 & 3 \\
\hline $\begin{array}{l}\text { Density variation range } \\
{\left[\begin{array}{c}\text { min } \\
\text { max }\end{array}\right.}\end{array}$ & {$[50,50]^{\mathrm{a}}$} & {$[40,60]$} & {$[30,70]$} & {$[20,80]$} \\
\hline${ }^{\mathrm{a} C o n}$ Constant density of $50 \mathrm{~kg} / \mathrm{m}^{3}$ (nongradient).
\end{tabular}

TABLE 3: Average increases of the flutter speeds for various GS and GF compared with the sandwich panel with no gradient change.

\begin{tabular}{lccc}
\hline & GF1 & GF2 & GF3 \\
\hline GS1 & $2.33 \%$ & $4.07 \%$ & $26.58 \%$ \\
GS2 & $1.94 \%$ & $3.69 \%$ & $5.32 \%$ \\
GS3 & $-0.10 \%$ & $-0.58 \%$ & $-1.45 \%$ \\
\hline
\end{tabular}

changes of the foam cores (GF) increase, though the total masses of the cores keep constant. Also, the velocity contours are continuous within the feasible lamination parameter region, all with the second mode as the critical vibration mode. Table 3 gives the average increases of the flutter speeds for various grading strategies and grading factors compared with the sandwich panel with no gradient change. Moreover, density grading strategy in the chord-wise direction (GS1) has the most obvious influence on the flutter speed, and density diagonal grading across the panel (GS3) has less influence compared with the other two grading strategies. And the diagonal density grading strategy can lead to minor decrease of the flutter speed.

4.2.2. Flutter Velocity Contour for Nonorthotropic Panel with Gradient Foam. When $V_{3}$ is positive, the bending-torsional flutter mode still remains the same as the orthotropic sandwich panel [9]. When $V_{3}$ is negative, there may be another flutter mode within part of the lamination parameter region (shown as Figure 6), with the third mode as the critical vibration mode. Two sets of lamination parameters in Figure 6 are chosen to examine the effect of laminate configurations on the flutter modes:

$$
\begin{aligned}
& \text { Point B: } V_{1}=-0.4, V_{2}=-0.2, V_{3}=-0.6, \\
& \text { Point C: } V_{1}=0.4, V_{2}=-0.2, V_{3}=-0.6
\end{aligned}
$$

Figure 7 shows the histories of the damping and frequency of the first four modes for the two cases.

Figure 8 details the flutter speed of the two sets with various gradient factors. For the two sets, density grading strategy in the chord-wise direction (GS1) has the most obvious influence on the flutter speed. For Point $\mathrm{C}$, the flutter speed of the sandwich panel increases when the gradient changes of the foam cores (GF) increase with the total masses of the cores keeping constant for GS1 and GS2, while, for point $B$, there occurs a decrease of the flutter speed compared with the nongradient panel for GS1 and GS2. Gradient change has the potential to increase the flutter speed. And the diagonal density grading (GS3) strategy can lead to minor decrease 


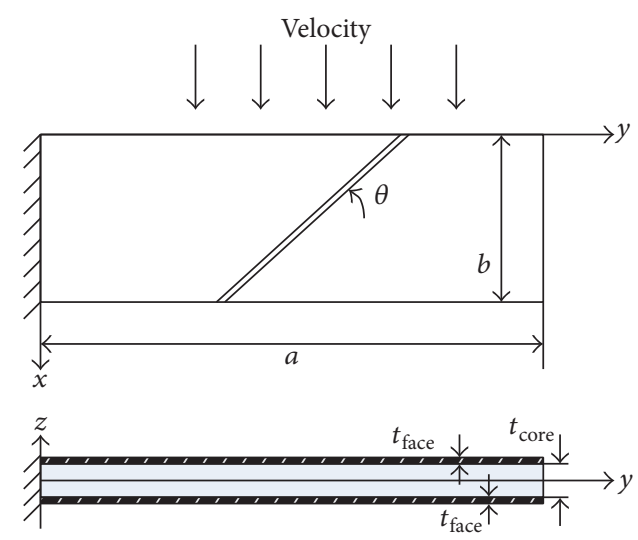

FIGURE 1: Cantilevered sandwich panel.

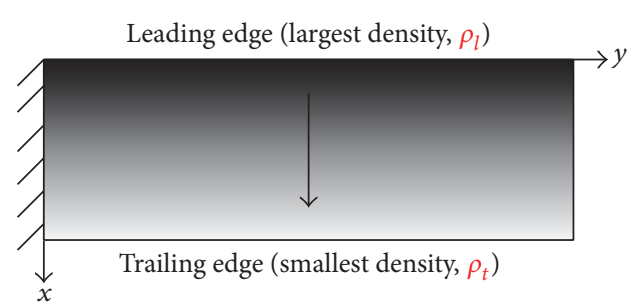

(a) Density grading in the chord-wise direction

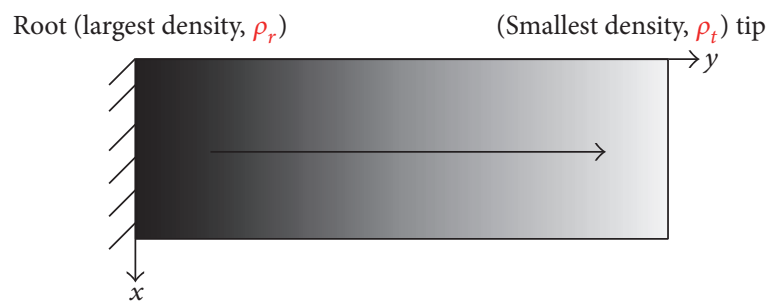

(b) Density grading in the span-wise direction

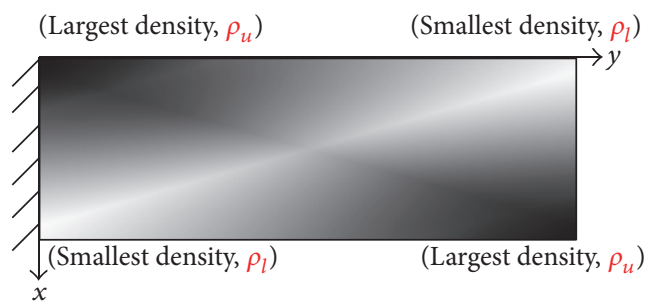

(c) Density diagonal grading across the $x y$ plane

FIGURE 2: Material grading across the sandwich panel [2].

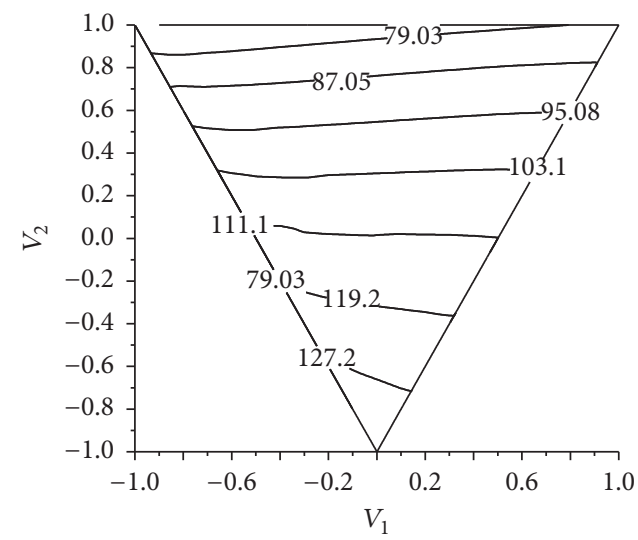

FIGURE 3: Flutter velocity contours for orthotropic sandwich panel with no gradient change $\left(V_{3}=0, \mathrm{GF}=0\right)$.

of the flutter speed for both sets. This is because the flutter characteristic is dependent on several other factors: wing sweep, aspect ratio, and the stiffness distribution. However, it shows that the proper gradient of the foam has the potential the flutter speed of the sandwich pane.

\section{Numerical Optimization Example}

5.1. Numerical Example Description. Minimum weight design of cantilevered sandwich panel as shown in Figure 1 with the flutter and divergence velocity constraints is 

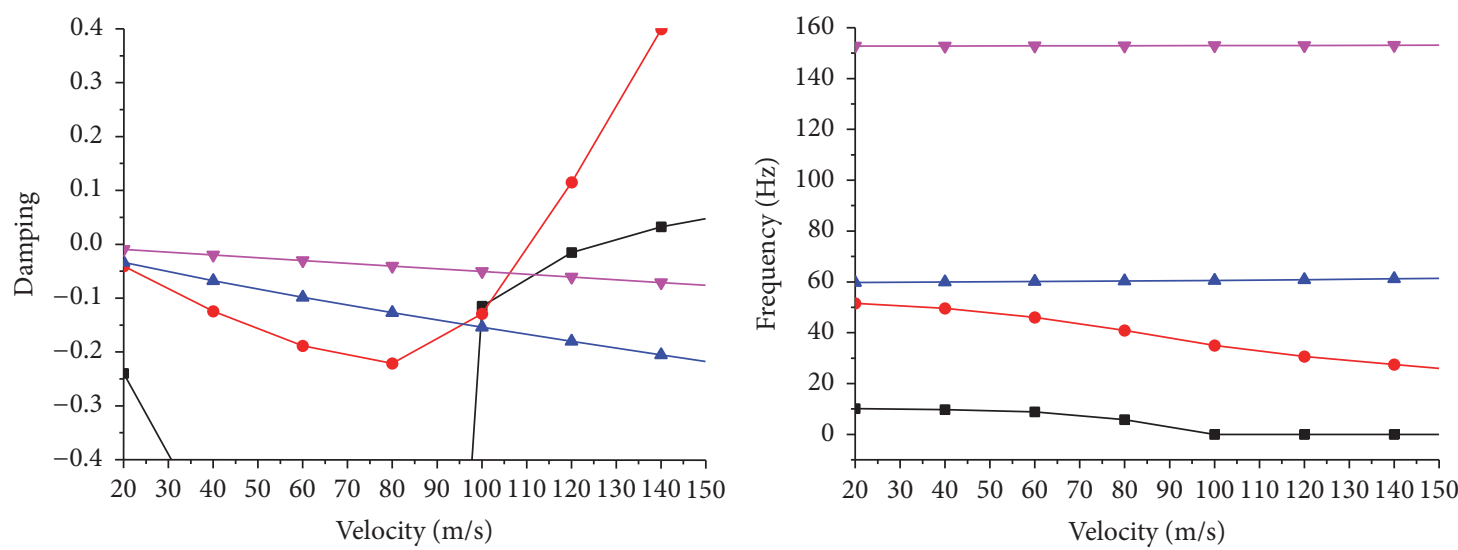

$\rightarrow$ Mode 1

$$
\neg \text { Mode } 3
$$

$\rightarrow$ Mode 1

Mode 2

- - Mode 3

$\rightarrow$ Mode 4

FIGURE 4: $V$ - $g$ and $v$ - $f$ curves of quasi-isotropic panel $\left(V_{1}=V_{2}=V_{3}=0\right)$.

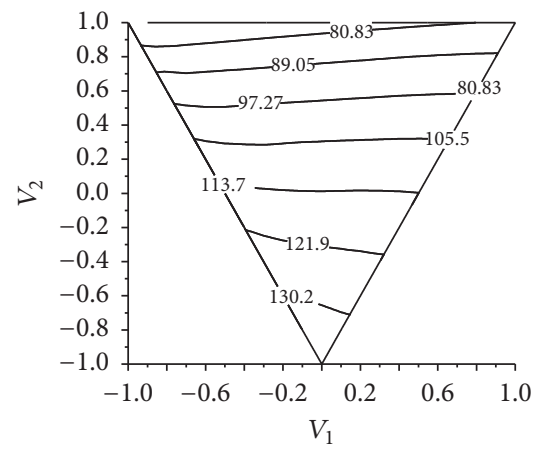

(a) $\mathrm{GF}=1(\mathrm{GS} 1)$

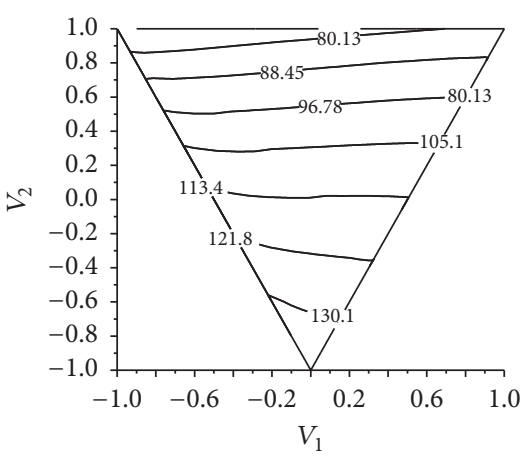

(d) $\mathrm{GF}=1(\mathrm{GS} 2)$

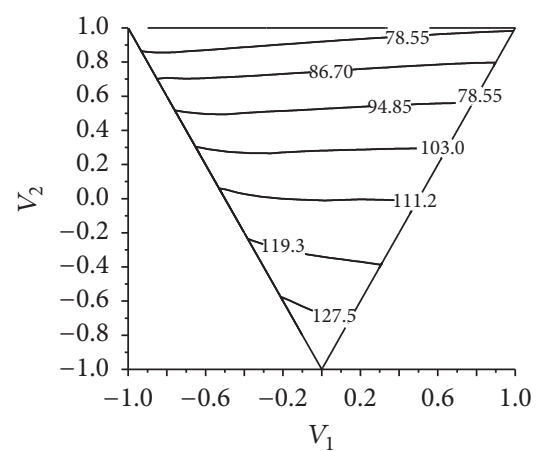

(g) $\mathrm{GF}=1(\mathrm{GS} 3)$

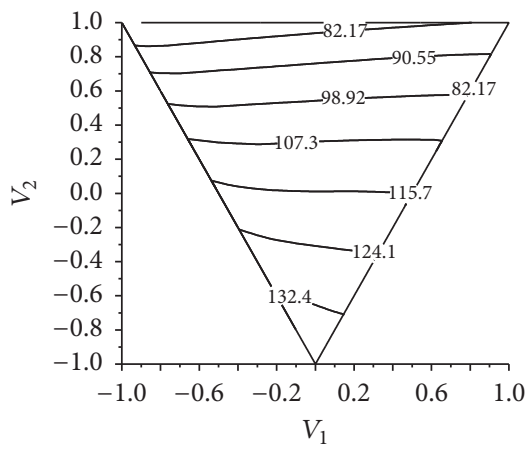

(b) $\mathrm{GF}=2(\mathrm{GS} 1)$

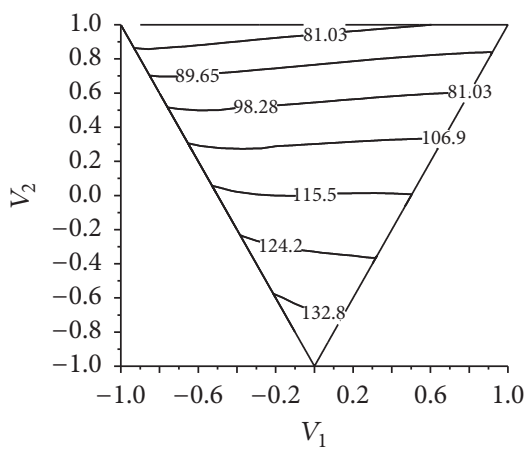

(e) $\mathrm{GF}=2(\mathrm{GS} 2)$

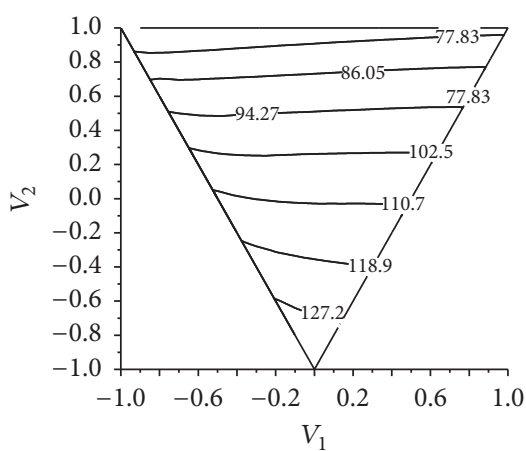

(h) $\mathrm{GF}=2(\mathrm{GS} 3)$

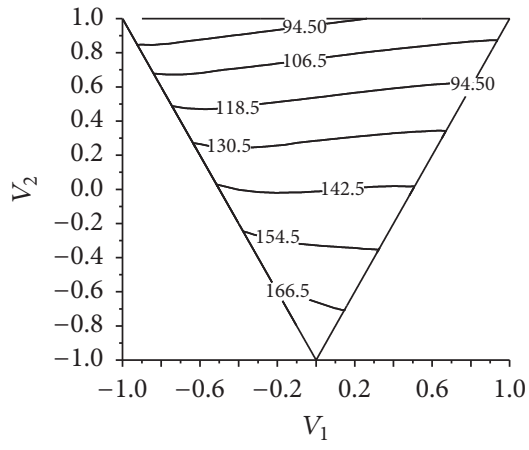

(c) $\mathrm{GF}=3(\mathrm{GS} 1)$

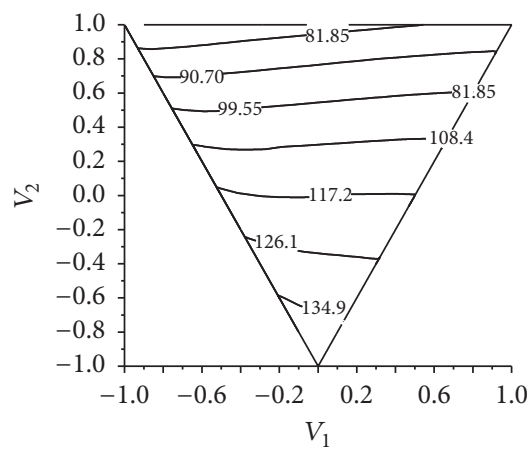

(f) $\mathrm{GF}=3(\mathrm{GS} 2)$

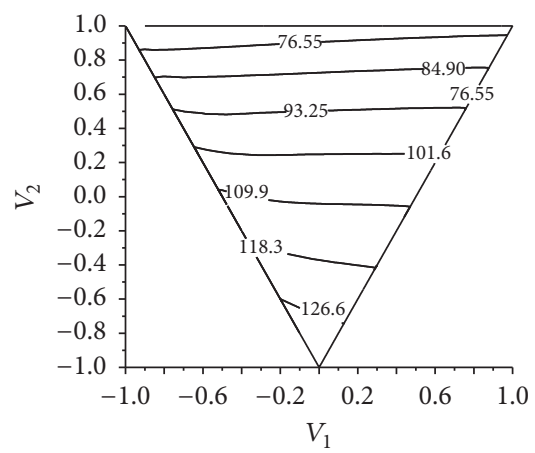

(i) $\mathrm{GF}=3(\mathrm{GS} 3)$

FIGURE 5: Flutter velocity contours for orthotropic sandwich panel $\left(V_{3}=0\right)$ with various gradient changes. 


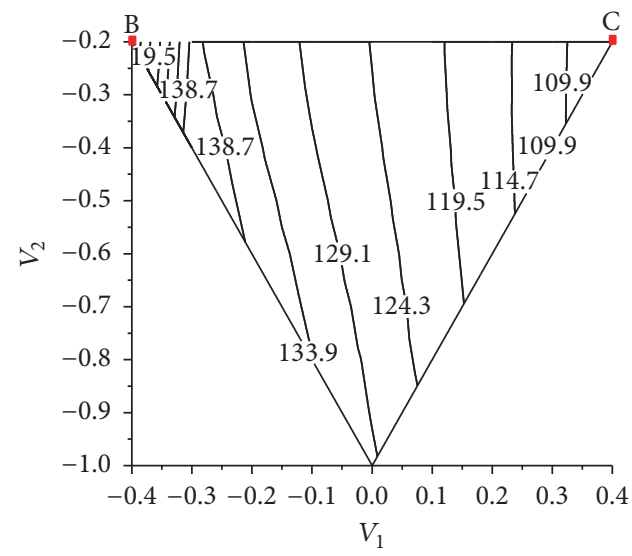

FIGURE 6: Flutter velocity contours for nonorthotropic sandwich panel with no gradient change $\left(V_{3}=-0.6, \mathrm{GF}=0\right)$.

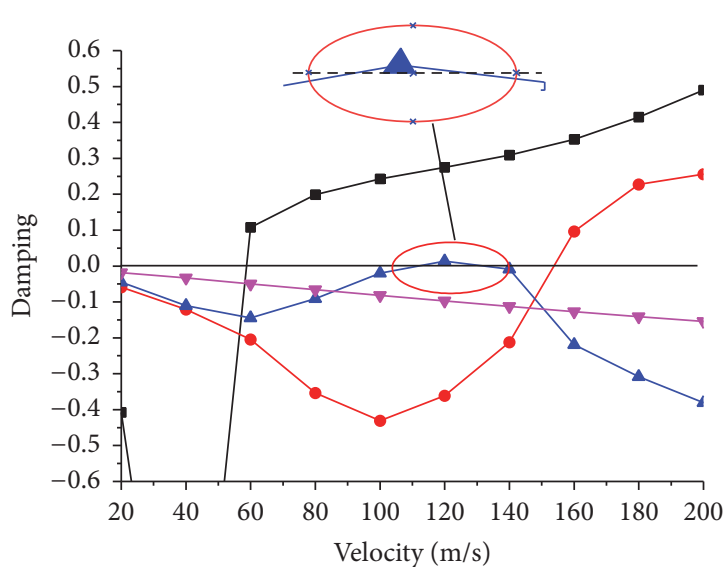

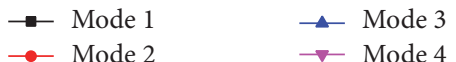

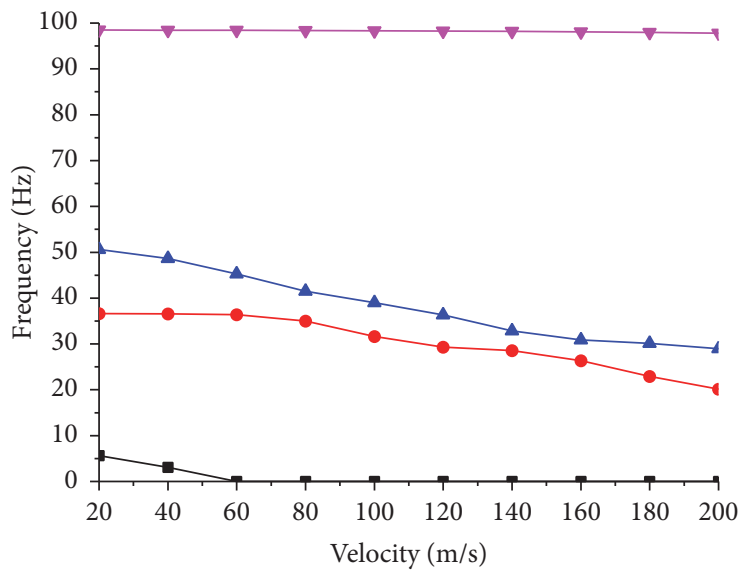

$\rightarrow-$ Mode 1

$\rightarrow$ Mode 2

- $\_$Mode 3

$\rightarrow$ Mode 4

(a) Point B

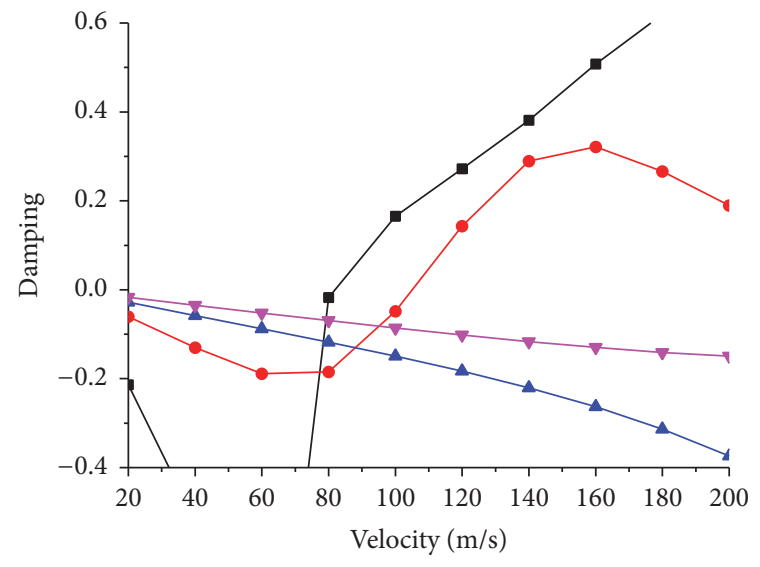

- Mode 1

$\rightarrow$ Mode 2 $\rightarrow$ Mode 3

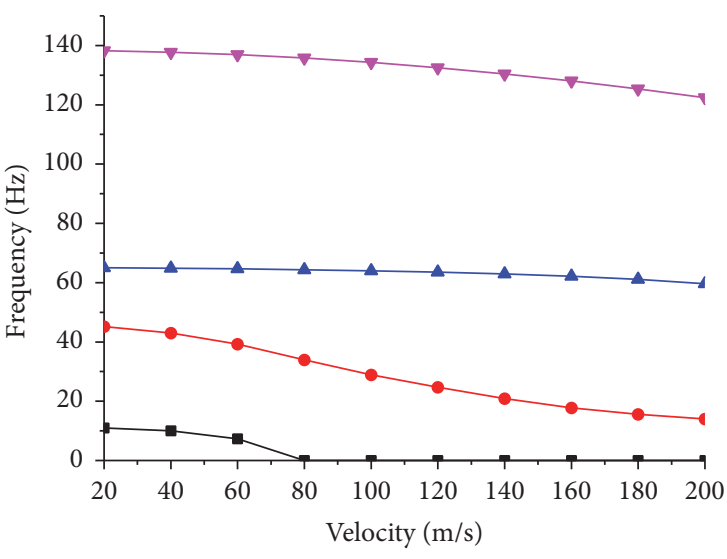

$\rightarrow$ Mode 3

(b) Point C

Figure 7: $V-g$ and $v$ - $f$ curves of the two points. 


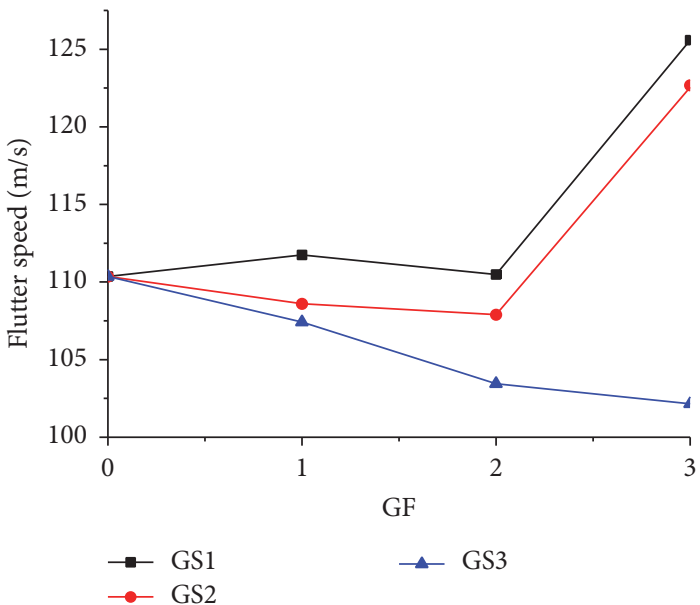

(a) Point B

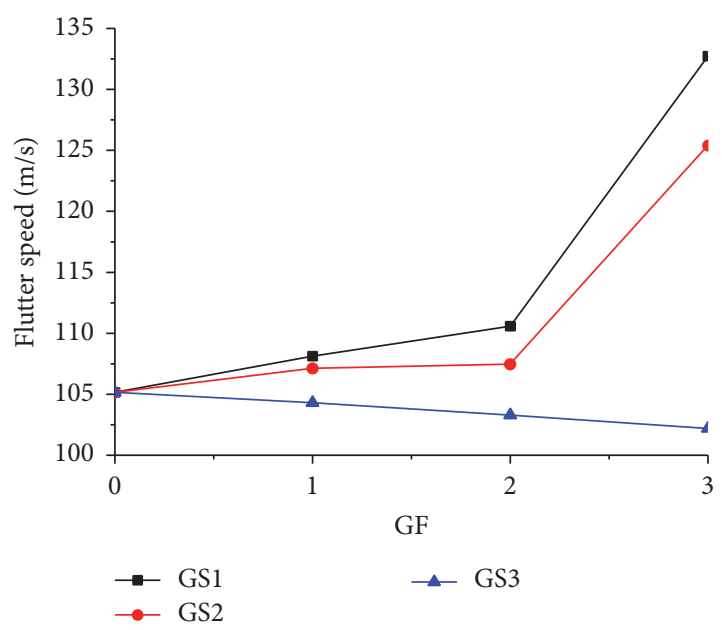

(b) Point C

FIGURE 8: Flutter speed of the two sets with various GS and GF.

carried out. The design variables include thickness and membrane lamination parameters of facesheet $\left(t_{\text {face }}, V_{1}\right.$, $\left.V_{2}, V_{3}\right)$, thickness, and density distribution of foam core $\left(t_{\text {core }}, \rho_{\text {core }}^{\min }, \rho_{\text {core }}^{\max }\right)$ because the density grading strategy in the chord-wise direction (GS1) has the most obvious influence on the flutter speed, so the GS1 is chosen as density grading strategy for foam core. The critical speed is assumed not less than $130 \mathrm{~m} / \mathrm{s}$. The constraints of lamination parameters $V_{1}$, $V_{2}$, and $V_{3}$ are described in (11), and the bound constraints of the $t_{\text {face }}, t_{\text {core }}, \rho_{\text {core }}^{\min }$, and $\rho_{\text {core }}^{\max }$ are assumed.

The optimization problem can be stated as follows:

$$
\begin{aligned}
\text { min: } & \text { mass }_{\text {face }}+\text { mass }_{\text {core }} \\
\text { s.t. } & v_{\text {critical }}=\min \left[v_{f}, v_{D}\right] \geq 130 \mathrm{~m} / \mathrm{s} ; \\
& 2\left|V_{1}\right|-V_{2}-1 \leq 0 ; \\
& 2\left|V_{3}\right|+V_{2}-1 \leq 0 ; \\
& t_{\text {face }} \in[0.000125 \mathrm{~m}, 0.000625 \mathrm{~m}] \\
& t_{\text {core }} \in[0.005 \mathrm{~m}, 0.01 \mathrm{~m}] \\
& \rho_{\text {core }}^{\max } \in\left[20 \mathrm{~kg} / \mathrm{m}^{3}, 80 \mathrm{~kg} / \mathrm{m}^{3}\right] ; \\
& \rho_{\text {core }}^{\min } \in\left[20 \mathrm{~kg} / \mathrm{m}^{3}, 80 \mathrm{~kg} / \mathrm{m}^{3}\right] ; \\
& \rho_{\text {core }}^{\min } \leq \rho_{\text {core }}^{\max } \\
\text { design variables: } & t_{\text {core }}, t_{\text {face }}, \rho_{\text {core }}^{\min }, \rho_{\text {core }}^{\max }, V_{1}, V_{2}, V_{3} .
\end{aligned}
$$

5.2. Optimization Algorithm. Because of the ability to deal with the continuous global optimization problem with a nonlinear objective function, particle swarm optimization (PSO) is an evolutionary global algorithm and has become more and more popular. PSO was first proposed by Kennedy and Eberhart $[15,16]$. It is observed that a swarm of birds or insects search for food in a very typical manner. If one member of the swarm finds a desirable path to go, the rest of the particles will follow quickly. Each particle searches for the best in its locality with learning from its own experience. Additionally, each member learns from the others, typically from the best performer among them. PSO has been successfully applied to some engineering and structural problems.

The basic steps in the PSO algorithm are as follows.

Step 1. Initialize the swarm with random position values and random initial velocities.

Step 2. Determine the velocity vector for each particle in the swarm using the knowledge of the best position obtained by each particle and the swarm as a whole and also the previous position of each particle in the swarm.

Step 3. Modify the current position of each particle using the velocity vector and the previous position of each particle.

Step 4. Repeat from Step 2 until the stop criterion is achieved.

The velocity vector of each particle is calculated as follows:

$$
v_{k}^{i}=w v_{k-1}^{i}+c_{1} r_{1}\left(p^{i}-x_{k-1}^{i}\right)+c_{2} r_{2}\left(p_{k-1}^{g}-x_{k-1}^{i}\right),
$$

where the superscript $i$ denotes the particle and the subscript $k$ denotes the iteration number; $v$ denotes the velocity and $x$ denotes the position; $r_{1}$ and $r_{2}$ are uniformly distributed random numbers in the interval $[0,1] ; c_{1}$ and $c_{2}$ are the acceleration constants; $w$ is the inertia weight; $p^{i}$ is the best position attained by the particle $i$ in the swarm so far and $p_{k-1}^{g}$ is the global best position attained by the swarm at iteration $k-1$.

The position of each particle at iteration $k$ is calculated using the formula:

$$
x_{k}^{i}=x_{k-1}^{i}+v_{k}^{i}
$$


TABLE 4: Optimum design variables and laminate configuration.

\begin{tabular}{|c|c|c|c|c|c|c|c|}
\hline$t_{\text {core }}(\mathrm{mm})$ & $t_{\text {face }}(\mathrm{mm})$ & $\rho_{\text {core }}^{\min }\left(\mathrm{kg} / \mathrm{m}^{3}\right)$ & $\rho_{\text {core }}^{\max }\left(\mathrm{kg} / \mathrm{m}^{3}\right)$ & $V_{1}$ & $V_{2}$ & $V_{3}$ & Sandwich configuration $^{\mathrm{a}}$ \\
\hline 10 & 0.125 & 20 & 37.64 & 0 & -1 & -0.076 & {$\left[45_{0.05775 \mathrm{~mm}} /-45_{0.06725 \mathrm{~mm}} / \text { foam }_{5 \mathrm{~mm}}\right]_{\mathrm{s}}$} \\
\hline
\end{tabular}
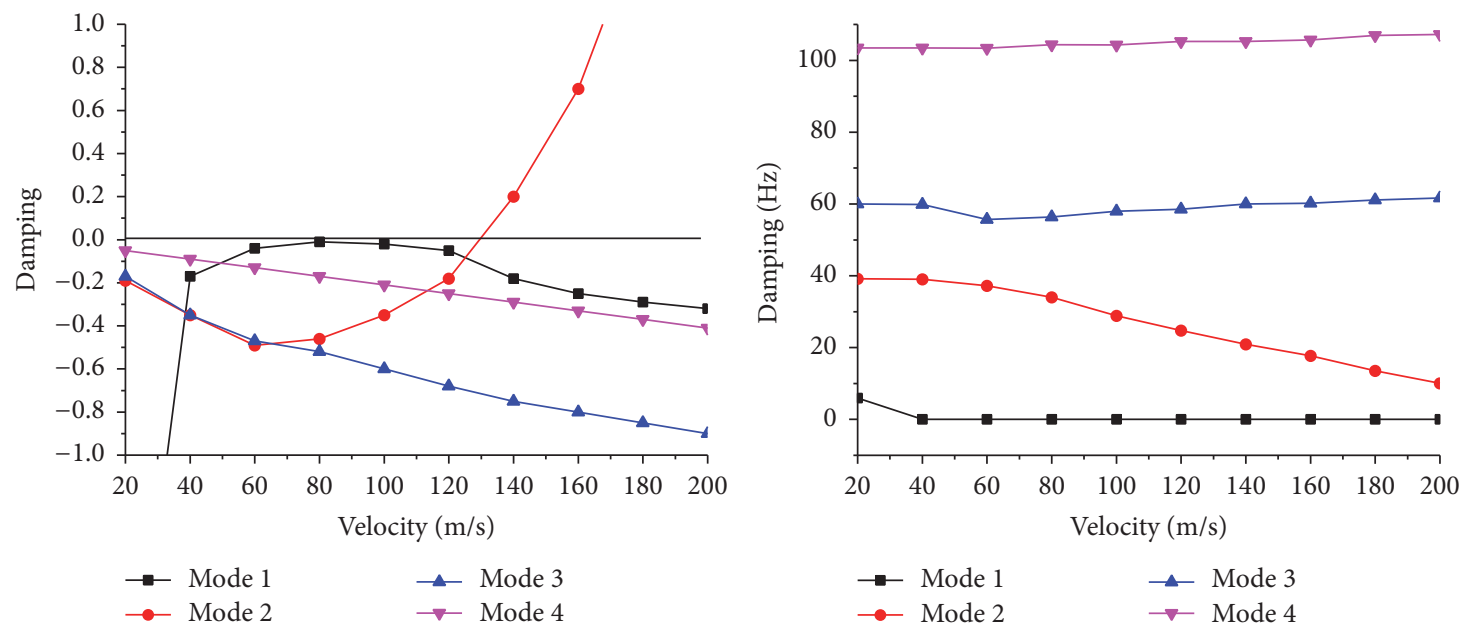

Figure 9: $V-g$ and $v$ - $f$ curves of the optimum result.

5.3. Results. According to (9-11) of [9], with the optimum facesheet thickness $(0.125 \mathrm{~mm})$ and optimum lamination parameters $\left(\left[V_{1}, V_{2}, V_{3}\right]=[0,-1,-0.076]\right)$, the corresponding layer thickness of facesheet can be obtained $\left(\left[n_{0}, n_{90}, n_{45}, n_{-45}\right]=[0,0,0.05775 \mathrm{~mm}, 0.06725 \mathrm{~mm}]\right)$. And the density distribution of the foam core is $\left[\rho_{\text {core }}^{\min }, \rho_{\text {core }}^{\max }\right]=$ $[20,37.64] \mathrm{kg} / \mathrm{m}^{3}$. So the optimum sandwich configuration is obtained as $\left[45_{0.05775 \mathrm{~mm}} /-45_{0.06725 \mathrm{~mm}} / \text { foam }_{5 \mathrm{~mm}}\right]_{\mathrm{s}}$, shown in Table 4. The speeds of flutter and divergence of the optimum sandwich configuration are $130.00 \mathrm{~m} / \mathrm{s}$ and $213.95 \mathrm{~m} / \mathrm{s}$, respectively, shown as Figure 9.

\section{Conclusions}

In this paper, the flutter speed of a cantilevered sandwich panel is studied using lamination parameters of composite facesheet, with influence of density gradient on sandwich panel considered. The results show that the flutter speed of the sandwich panel has the potential to increase when the proper gradient changes of the foam cores (GF) increase for chordwise strategy and span-wise strategy with the total mass of the core constant. A minimum weight design of composite sandwich panel with lamination parameters of facesheet and density distribution of foam core as design variables was conducted using PSO. The results show that the PSO algorithm can be effective for the lamination parametersbased optimizaiton problem.

The paper conducts a series of flutter analysis for a range of functionally graded core of composite sandwich. The previous studies in this area have already shown that the flutter characteristics are sensitive to the wing geometry (e.g., aspect ratio and sweep) as well as material properties and that the conclusion drawn in this paper is a little simplistic. Further research will be focused on careful analysis considering other key parameters based on the existing literature and offer a more comprehensive discussion.

\section{Competing Interests}

The authors declare that they have no competing interests.

\section{Acknowledgments}

The support for this work by the National Natural Science Foundation of China (11402204) is gratefully acknowledged.

\section{References}

[1] A. Attaran, D. L. Majid, S. Basri, A. S. Mohd Rafie, and E. J. Abdullah, "Structural optimization of an aeroelastically tailored composite flat plate made of woven fiberglass/epoxy," Aerospace Science and Technology, vol. 15, no. 5, pp. 393-401, 2011.

[2] P. D. Dunning, B. K. Stanford, H. A. Kim, and C. V. Jutte, "Aeroelastic tailoring of a plate wing with functionally graded materials," Journal of Fluids and Structures, vol. 51, pp. 292-312, 2014.

[3] T. Prakash and M. Ganapathi, "Asymmetric flexural vibration and thermoelastic stability of FGM circular plates using finite element method," Composites Part B: Engineering, vol. 37, no. 78, pp. 642-649, 2006.

[4] H. H. Ibrahim, M. Tawfik, and M. Al-Ajmi, "Thermal buckling and nonlinear flutter behavior of functionally graded material panels," Journal of Aircraft, vol. 44, no. 5, pp. 1610-1618, 2007.

[5] H. H. Ibrahim, M. Tawfik, and M. Al-Ajmi, "Non-linear panel flutter for temperature-dependent functionally graded material 
panels," Computational Mechanics, vol. 41, no. 2, pp. 325-334, 2008.

[6] H. M. Navazi and H. Haddadpour, "Aero-thermoelastic stability of functionally graded plates," Composite Structures, vol. 80, no. 4, pp. 580-587, 2007.

[7] S.-Y. Kuo, "Flutter of rectangular composite plates with variable fiber pacing," Composite Structures, vol. 93, no. 10, pp. 25332540, 2011.

[8] L. Librescu and K. Y. Maalawi, "Material grading for improved aeroelastic stability in composite wings," Journal of Mechanics of Materials and Structures, vol. 2, no. 7, pp. 1381-1394, 2007.

[9] P. Jin, B. Song, X. Zhong, T. Yu, and F. Xu, "Aeroelastic tailoring of composite sandwich panel with lamination parameters," Proceedings of the Institution of Mechanical Engineers, Part G: Journal of Aerospace Engineering, vol. 230, no. 1, pp. 105-117, 2016.

[10] V. Balabanov, O. Weckner, M. Epton, G. Mabson, E. Cregger, and A. W. Blom, "Optimal design of a composite sandwich structure using lamination parameters," in Proceedings of the 53rd AIAA/ASME/ASCE/AHS/ASC Structures, Structural Dynamics and Materials Conference, Honolulu, Hawaii, USA, April 2012.

[11] H. Fukunaga and G. N. Vanderplaats, "Stiffness optimization of orthotropic laminated composites using lamination parameters," AIAA journal, vol. 29, no. 4, pp. 641-646, 1991.

[12] D. B. Xiao, L. Mu, and G. P. Zhao, “The influence of correlating material parameters of gradient foam core on free vibration of sandwich panel," Composites Part B: Engineering, vol. 77, pp. 153-161, 2015.

[13] L. J. Gibson and M. F. Ashby, Cellular Solids: Structure and Properties, Cambridge University Press, Cambridge, UK, 2nd edition, 1997.

[14] W. P. Rodden and E. H. Johnson, MSC/Nastran Aeroelastie Analysis User's Guide V68, MSC, Software Corporation, Los Angeles Calif, USA, 1994.

[15] J. Kennedy and R. Eberhart, "Particle swarm optimization," in Proceedings of the IEEE International Conference on Neural Networks, pp. 1942-1948, Perth, Australia, December 1995.

[16] R. Eberhart and J. Kennedy, "New optimizer using particle swarm theory," in Proceedings of the 6th International Symposium on Micro Machine and Human Science (MHS '95), pp. 3943, Nagoya, Japan, October 1995. 


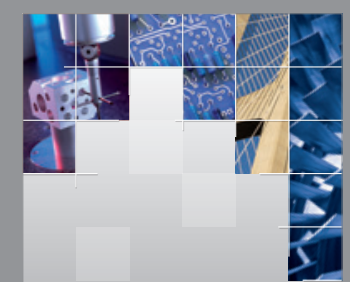

\section{Enfincering}
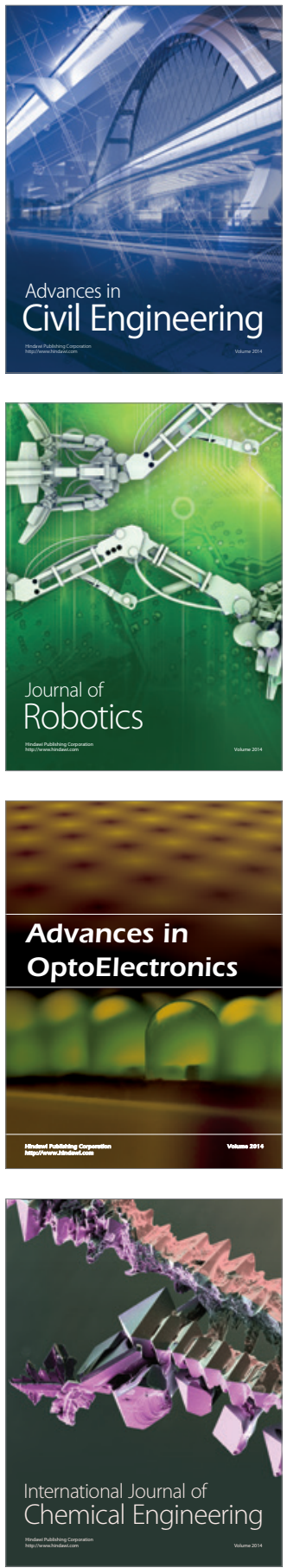

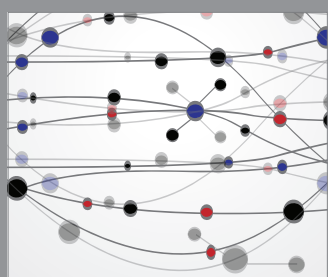

The Scientific World Journal

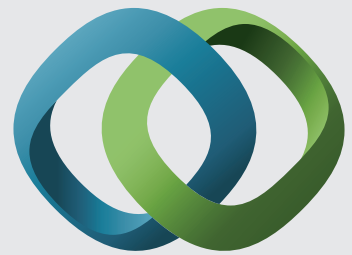

\section{Hindawi}

Submit your manuscripts at

http://www.hindawi.com
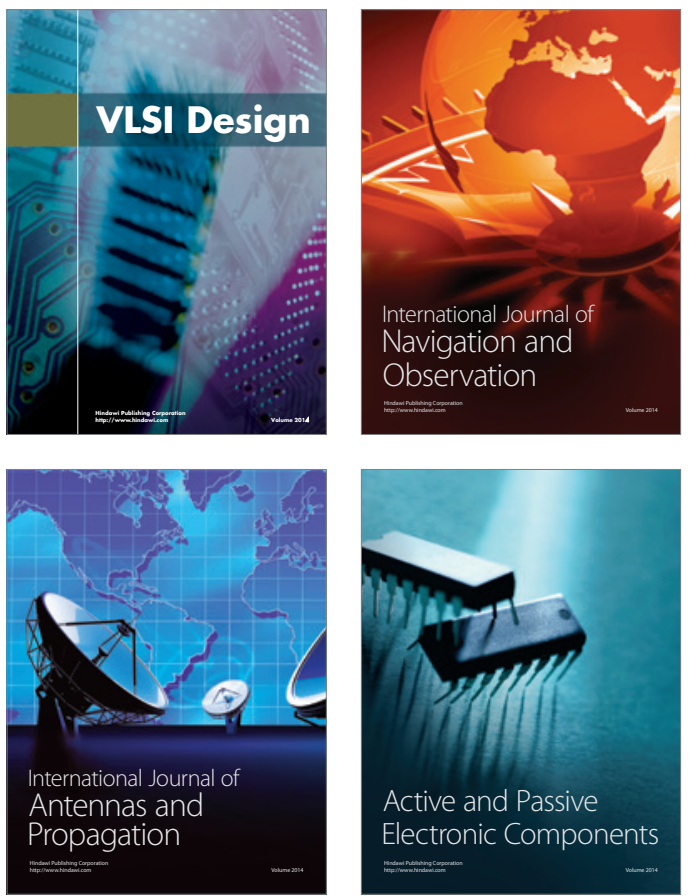
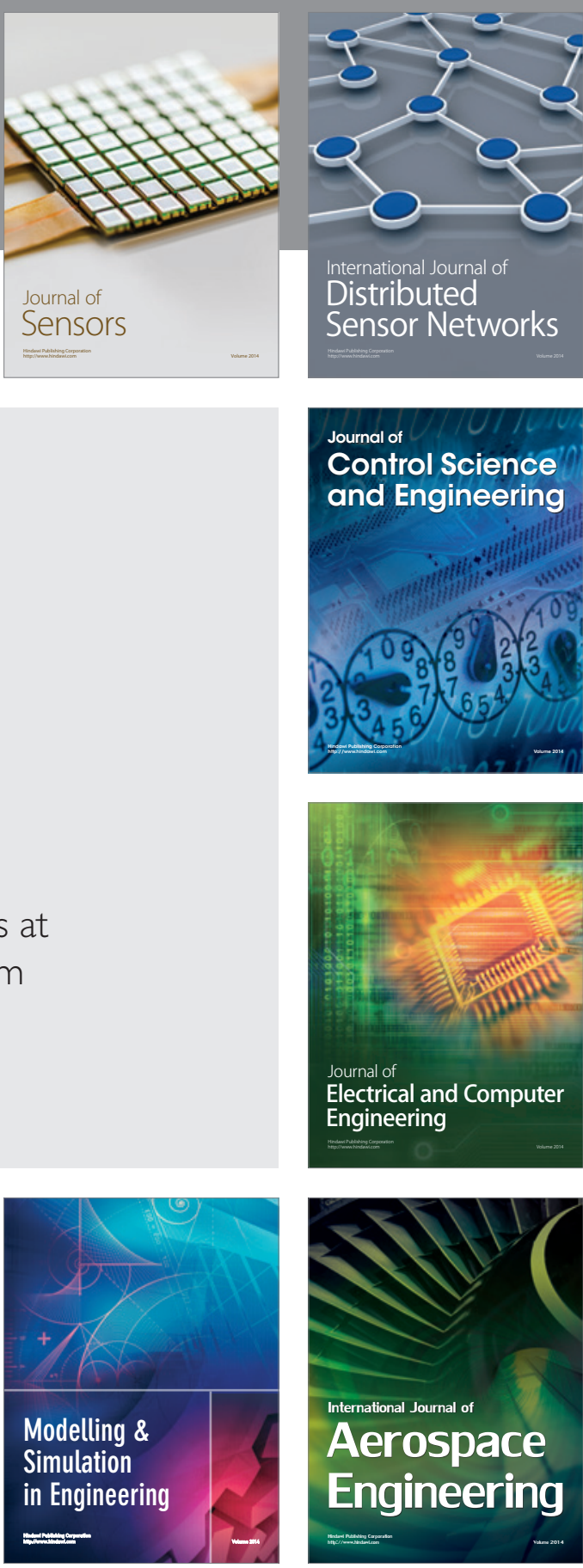

International Journal of

Distributed

Sensor Networks

Journal of

Control Science

and Engineering
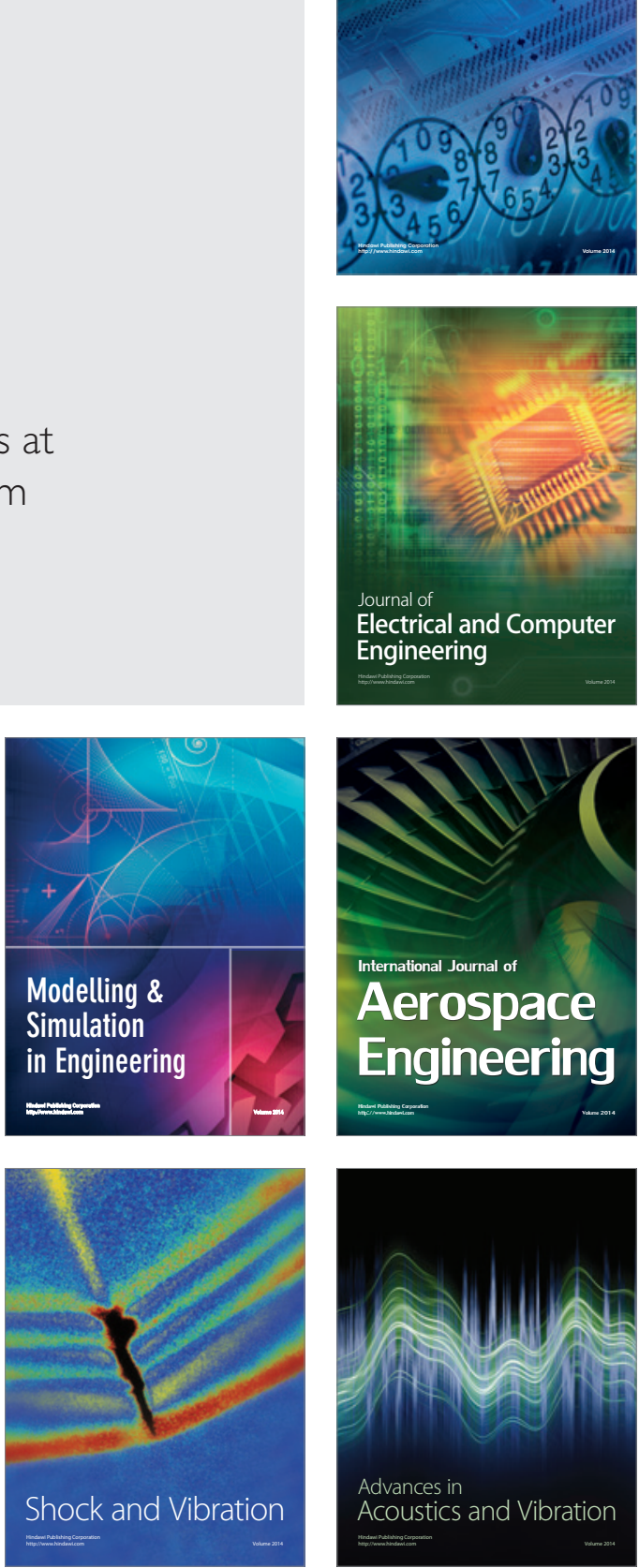